\title{
A governança e o planejamento na perspectiva regional de saúde
}

\author{
I ${ }^{1}$ Renan Carlos Freitas da Silva, ${ }^{2}$ Erlene Roberta Ribeiro dos Santos, ${ }^{3}$ Petrônio José \\ de Lima Martelli, ${ }^{4}$ José Eudes Lorena Sobrinho, ${ }^{5}$ Camila da Costa Lima Souto I
}

Resumo: O princípio da descentralização do SUS percorreu uma longa trajetória desde sua fundação. As normativas instituídas ao longo do tempo apontaram um processo da regionalização em detrimento da municipalização. A publicação do Decreto $n^{\circ} 7.508 / 11$ legitimou as regióes de saúde e seu respectivo espaço de pactuação para a elaboração do planejamento e a tomada de decisão. Considerando tais aspectos, o estudo analisou a governança e o planejamento em saúde na II Região de Saúde do Estado de Pernambuco, por meio de estudo qualitativo, utilizando a análise documental proveniente das atas e pautas da Comissão Intergestores Regional e a análise de conteúdo de entrevistas semiestruturadas realizadas com os gestores municipais da região. Os resultados demonstraram o protagonismo da CIR na governança regional, apesar das evidentes fragilidades no processo de planejamento regional e nas estruturas das redes de atenção à saúde.

> Palavras-chave: sistemas de saúde; regionalização; governança.

\author{
1 Universidade Federal de \\ Pernambuco. Recife-PE, Brasil \\ (renancarlos_eaf@hotmail.com). \\ ORCID: 0000-0001-7728-330X \\ ${ }^{2}$ Universidade Federal de \\ Pernambuco. Recife-PE, Brasil \\ (erleneroberta@uol.com.br). \\ ORCID: 0000-0003-3334-3408 \\ ${ }^{3}$ Universidade Federal de \\ Pernambuco. Recife-PE, Brasil \\ (petroniocarla@uol.com.br). \\ ORCID: 0000-0001-6920-6435 \\ ${ }^{4}$ Universidade de Pernambuco. \\ Recife-PE, Brasil (eudeslorena@ \\ hotmail.com). ORCID: 0000-0001- \\ 7820-735X \\ ${ }^{5}$ Universidade Federal de \\ Pernambuco. Recife-PE, Brasil \\ (camila_souto90@hotmail.com). \\ ORCID: 0000-0003-3531-1725
}

Recebido em: 17/01/2020 Aprovado em: 24/08/2020 Revisado em: 10/09/2020 


\section{Introdução}

A trajetória da descentralização, um dos princípios organizativos do SUS, tomou corpo por meio de normas legais instituídas pelo Ministério da Saúde, como a Normas Operacionais Básicas (NOB), a Norma Operacional de Assistência à Saúde (NOAS) e o Pacto pela Saúde. Tal princípio foi marcado pelo processo de municipalização, incentivando os municípios a ampliarem seus serviços de saúde com o objetivo de garantir a universalidade do sistema (LIMA; VIANA; MACHADO, 2014; LOUVISON; MENDES, 2015).

No entanto, tais normas não foram capazes de se adequar às diversas realidades dos territórios, uma vez que a desconsideração do papel das esferas estaduais acentuou as atribuiçóes dos municípios na execução dos serviços. A partir desse contexto, a homologaçáo do Decreto 7.508/2011 alguns anos depois foi uma das principais estratégias que permitiram uma nova roupagem para a descentralização, a qual passou a se conformar sob um espaço de gestão regional formada pelo ente estadual e os municipios límitrofes definidos por Planos Diretores de Regionalização. A partir desse cenário, a conformação das regiōes de saúde foi pautada no território e na cooperação entre atores envolvidos, tomando como premissa a coordenação de políticas que integrassem as pautas de planejamento e de gestão para as dinâmicas territoriais (LIMA; VIANA; MACHADO, 2014; SANTOS, 2017).

Nessa seara, o reflexo da descentralização do SUS garantiu maior autonomia dos entes municipais e estaduais nos processos decisórios. Permitiu que a governança fosse trilhada, a partir de arranjos que compartilhassem objetivos comuns, ancorados na tutela do acesso universal à saúde. Essa concepção admite que a governança no SUS possa ser aportada em um modelo de rede colaborativa (MILAGRES; SILVA; REZENDE, 2016).

A condução dessa governança pode ser compreendida pelo termo "governança territorial”, que expressa as iniciativas ou açôes territoriais organizadas pelos municípios, estados, regiōes e união para conduzir temáticas de interesses coletivos, a partir do envolvimento conjunto e cooperativo de diferentes atores sociais, econômicos e institucionais. O presente estudo utiliza essas reflexôes como arcabouço teórico relativo à governança (DALLABRIDA, 2011). Desse modo, as Regiôes de Saúde, uma vez fortalecidas, tornaram-se um dos principais locais para a governança, que envolve a saúde do território, com a possibilidade de promover novos arranjos 
mediante as necessidades e especificidades. Esse fortalecimento requer das regiōes de saúde um processo de planejamento regional, por meio de uma capacidade de contribuir para melhor alocação e distribuição de recursos na região (MEDEIROS, 2013; SANTOS; GIOVANELLA, 2014; VIANA; LIMA, 2013).

As regiōes de saúde devem ser estruturadas para promoverem as ações e serviços de saúde. Institucionalizados pela política pública em determinado espaço regional, representando o encontro da esfera local com a regional como instância resolutiva, abrangente e com potencialidades para o desempenho da condução e oferta do cuidado para além dos limites municipais (ALMEIDA et al., 2016; SANTOS, 2017). Nessa perspectiva, os gestores precisam estar preparados para atuar em um ambiente complexo, considerando a necessidade de tecnologias apropriadas e de competências coordenadas entre os entes federativos e precisam estar conectados com os saberes da sociedade, responsabilizados pela alocação dos recursos e insumos, de forma efetiva, que traduzam em uma boa prestaçáo de serviço aos usuários (SANTOS; LEITE; SILVA, 2018).

A partir dessa perspectiva relativa à governança quanto à condução do sistema de saúde local, reforça-se o entendimento para a abertura de mecanismos capazes de ofertar respostas às demandas de saúde com relevantes aspectos regionais. Assim, a tomada de decisão nas regiôes de saúde pode gerar um grande impacto, uma vez que envolve estrutura, processos de produção e açóes e serviços de saúde por meio de açôes coordenadas entre os níveis de complexidade (atenção primária, média complexidade e alta complexidade) que visam ao atendimento às demandas de saúde da população com a prestaçáo adequada dos serviços (SANTOS, 2017; MENDES, 2010; SILVA; SANTOS; MENDES, 2012).

Dentre os aspectos que devem ser considerados, a partir da necessidade de pautar a efetividade dos espaços de participação, chama a atenção aqueles de atendimento aos objetivos embasados no planejamento, influenciando diretamente os processos de tomada de decisão dos gestores (RICARDI; SHIMIZU; SANTOS, 2017). Nesse contexto, o planejamento em saúde busca contemplar as necessidades humanas, orientando a identificação e a resolução de problemas que afetam a sociedade. Para Paim e Teixeira (2006), esses problemas podem ser denominados de "estado de saúde" e "serviços de saúde". O primeiro se refere aos agravos, doenças, acidentes e outras adversidades que atingem os usuários. $\mathrm{O}$ segundo se relaciona às situaçôes que envolvem infraestrutura, organização, gestão, financiamento e outros. Assim, 
o planejamento lida com contextos que se relacionam diretamente às necessidades humanas e dos serviços para seu atendimento.

Para tanto, o planejamento deve partir da formulação de um processo ascendente e participativo, o qual se aproxime do conceito de processo de trabalho e permita abordá-lo como organizador de saberes e práticas. E, então, extrapolar o próprio arcabouço normativo e contribuir diretamente para o exercício da cidadania, permitindo o posicionamento do usuário como coparticipante do processo de planejamento e das políticas de saúde de seu território (SILVA et al., 2015). Porém, os significativos avanços no processo de regionalização e de planejamento não são, por si sós, suficientes para garantir um processo de descentralização de recursos que gere maior autonomia para as regióes de saúde e dos municípios. Além disso, as tentativas legais, para formação das regiôes de saúde, não foram satisfatórias para acabar com o caráter clientelista, privatista e ineficiente do Estado brasileiro (SANTOS et al., 2015; SANTOS; CAMPOS, 2015).

Nesse sentido, o presente estudo tem o objetivo de analisar a configuração da governança e do planejamento em saúde na esfera da II Regiấo de Saúde do Estado de Pernambuco.

\section{Metodologia}

A tipologia selecionada foi um estudo de caso, o que possibilitou a imersão na realidade regional de saúde, a partir de seus aspectos e peculiaridades, quanto ao planejamento e governança em saúde (YIN, 2005). O estudo foi realizado na II Regiáo de Saúde do Estado de Pernambuco, composta por 20 municípios. Para a realização das entrevistas, adotou-se como critério de inclusão gestores municipais de saúde que estivessem exercendo a função na II Região de Saúde de Pernambuco. E como critério de exclusão, gestores que apresentassem episódios de afastamento da função no periodo de seis meses anterior a realização da entrevista.

O estudo considerou 20 gestores municipais de saúde da II Região de Saúde. Após a aplicação dos critérios de elegibilidade, foram habilitados 14 gestores municipais de saúde com uma perda, totalizando 13 entrevistados. Foi utilizada a técnica da entrevista a partir de instrumento/roteiro não estruturado, sobre a percepção do sujeito acerca do planejamento em saúde, entraves e facilidades, governança e tomada de decisão. Após a validação do instrumento, foram realizadas as entrevistas 
com os sujeitos. O procedimento durou cerca de 40 minutos e foi aplicado in loco nas respectivas Secretarias Municipais de Saúde. Os dados coletados, a partir das entrevistas, foram interpretados por meio de uma planilha de acordo com as seguintes categorias de análise: governança, planejamento, regionalização e financiamento. As falas mais frequentes ou que obtiveram maior destaque na percepção do pesquisador foram comparadas com a literatura existente sobre o tema.

A técnica se baseou na metodologia proposta por Bardin (2011), que estabelece três grandes etapas: pré-análise, exploração do material e tratamento dos resultados e interpretação. A análise de conteúdo das entrevistas com os gestores municipais de saúde permitiu identificar os aspectos que estes emitem sobre os principais desafios e potencialidades para o exercício do planejamento e governança na região de saúde. Além disso, o estudo utilizou a sistematização da análise documental das atas e pautas das reunióes da CIR, conforme o quadro explicativo, composto por colunas, associando o documento ao procedimento de coleta de dados e o instrumento para registro. A análise documental é considerada uma operação ou um conjunto de operaçóes com o objetivo de representar o conteúdo de um documento com um olhar diferente do original, de modo que facilite, posteriormente, sua consulta e sua referência (BARDIN, 2011).

Quadro 1. Sistematização da análise documental. Recife-PE, 2018

\begin{tabular}{|c|c|c|}
\hline Documento & Procedimento De Coleta & Instrumento para Registro e Análise \\
\hline Atas/Pauta & Extração De Núcleo De Sentido & Matriz de Registro \\
\hline
\end{tabular}

Fonte: elaboração própria.

Procedeu-se à avaliação preliminar de cada documento sob o olhar dos seguintes elementos: contexto, autores, interesses, confiabilidade, natureza do texto e conceitos-chave. A apuração foi realizada por meio de leitura detalhada, utilizando a análise crítica dos documentos com sua caracterização, descrição e comentários, assim como efetuando o levantamento de assuntos recorrentes, codificação, decodificação, interpretação e inferência. Todas as açôes relacionadas ao objeto de estudo, identificadas nos documentos, foram destacadas. Operou-se uma releitura dos parágrafos acentuados e uma organização numa planilha de registro. Os sujeitos assinaram o Termo de Consentimento Livre e Esclarecido. As entrevistas foram gravadas com consentimento dos entrevistados e, posteriormente, transcritas. O 
estudo observou as normas da Resoluçáo n ${ }^{\circ}$ 466/2012 e foi aprovado no Comitê de Ética e Pesquisa sob o CAEE: 90828718.7.0000.5208.

\section{Resultados e Discussão}

O reconhecimento da potencialidade da CIR como espaço para governança em saúde foi percebido na maioria das respostas dos entrevistados, sinalizando sua relevância para governança e fortalecimento da regionalização em saúde. Segundo Silveira Filho et al. (2016), a CIR representou um importante espaço para a governança regional. Santos e Giovanella (2014) seguem a mesma linha, ao afirmar que a CIR foi a principal estratégia da governança regional, reunindo diferentes sujeitos responsáveis pela tomada de decisão, negociação e distribuição de recursos.

A partir da fonte de dados das atas, foi possível observar uma alta assiduidade dos secretários municipais e de representantes e técnicos municipais. Mendes et al. (2015) reforçam essa evidência, ao concluírem que a participação de outros atores denota a capacidade de apoio técnico na condução das reuniôes, favorecendo o diálogo para o reconhecimento e o enfrentamento das necessidades de saúde dos territórios. As entrevistas revelaram a ocorrência de trocas de gestores, resultante de atravessamento político-partidário, constatando dessa forma, forte influência política na região.

A clara experiência da cooperação regional e de solidariedade entre os entes garante autonomia e governabilidade com maior coordenação central. Por outro lado, a baixa autonomia dos secretários influenciados por incipiência técnica, atravessamento político-partidário e recursos financeiros insuficientes, dificulta a consolidação da governança na regiâo (GIOVANELA, 2014; MOREIRA; RIBEIRO; OUVERNEY, 2017).

As análises permitiram identificar forte tendência para negociaçôes marcadas por atravessamento de poder. Esse diferente arranjo de governança pode estar associado ao interesse político de um serviço regionalizado no território e à deficiência técnica dos atores envolvidos. Com efeito, Moreira, Ribeiro e Ouverney (2017) afirmaram que a institucionalização da CIR gerou conflitos próprios das relaçôes interfederativas entre o governo estadual e municipal, com visível favorecimento aos interesses do ente que detivesse mais poder, gerando pautas fragilizadas e maior preponderância estadual. 
Para Lima et al. (2017), as formas como se distribuem as funçôes e os recursos expressam relaçóes de poder que envolvem gestores e prestadores de serviços, condicionadas por dinâmicas regionais específicas. Dourado e Elias (2011) vão além, ao criticar, nas pactuaçóes na CIR, o que chamam de consensualismo, sem a lógica de decisóes coletivas, marcada pelos poderes estabelecidos. Esse cenário aponta desafios para a democratização do poder em nível local no SUS, que são marcados pelas antigas tradiçóes do clientelismo (FLEURY, 2014). Ainda, as reuniōes de CIR revelam dificuldades comuns e buscam estratégias para superação dos problemas na oferta e no acesso aos serviços entre os municípios, sendo um importante instrumento de debate e de fortalecimento da região (SILVEIRA FILHO et al., 2016).

Com relação ao tempo no cargo de gestão, mais de $80 \%$ dos gestores na região ocupam há menos de dois anos a função. As constantes trocas de gestores municipais de saúde refletem a descontinuidade nos processos de trabalho estabelecidos e podem condicionar modelos de gestão pautados na centralização, hierarquização e burocratização, reduzindo a capacidade gerencial do SUS (LORENZETTI et al., 2014). Considerando a complexidade da gestão do SUS, é fundamental que o gestor municipal possua um perfil com conhecimento e capacidade de gestáo, pois cabe aos atributos da função prover os serviços de saúde com eficiência e eficácia à população (ARCARI et al., 2018). Nesse sentido, a materialidade da governança em saúde deve ser compreendida em meio à capacidade dos gestores integrantes da política. $\mathrm{O}$ quadro institucional deve favorecer a participação e a negociação dos atores, a gestão de conflitos e, por fim, o estabelecimento de uma ação coordenada, voltada à direção de ações pautadas no alcance de metas e objetivos já definidos (GOYA et al., 2017).

Outra evidência quanto ao perfil dos gestores municipais diz respeito ao seu grau de escolaridade, mais de $85 \%$ dos gestores tinham formação na área da saúde e quase $70 \%$ possuíam pós-graduação. Arcari et al. (2018) afirmam ainda que a evolução nas demandas da gestáo pode estar elevando o grau de exigência no processo de trabalho do gestor, fato provavelmente associado com a escolaridade dos secretários que, em sua maioria, possuem curso superior. Fleury e Ouverney (2006) identificaram que grande parte dos secretários municipais de Saúde não havia ocupado esse cargo anteriormente, o que apenas reforça a necessidade de apropriação técnica desses gestores para assumirem a função. 
As dificuldades relacionadas à infraestrutura e aos processos de trabalho apenas corroboram os desafios para a sustentaçáo e articulação de parcerias entre ensino e serviço, educação e trabalho, agravadas, ainda, pela burocratização e indefinição de formas de gestão financeira, aplicada à Política de Educação que permeia as estruturas regionais (FRANÇA et al., 2017). A Comissão Integrada de Ensino e Serviço tem sido uma estratégia utilizada para o desenvolvimento da educação permanente em saúde nas regióes. Contudo, desafios ainda precisam ser superados para propor uma ideologia que seduza pela sua eficiência e aparência de novidade pedagógica (LEMOS, 2016; FRANÇA et al., 2017). É preciso, portanto, que mecanismos de incentivo à participação e à apropriação de gestores sobre os temas levantados, possam subsidiá-las quanto aos desafios postos na gestão do SUS regional.

Foi possível identificar, neste estudo, a importância da articulação interfederativa para superação dos problemas regionais de saúde, com uma relação direta entre as dificuldades do processo de planejamento e de tomada de decisão. Espaços como a CIR desenvolvem os mecanismos de coordenação e de cooperação para a regionalização do SUS. Essa interdependência federativa deve ser uma mola propulsora para a autonomia e a capacidade de negociação entre os entes.

A proposta de descontruir a herança da municipalização no processo de regionalização se fortalece por meio de uma regionalização solidária que deverá abarcar uma força conjunta dos atores para a superação dos desafios imbricados. Assim, somente decisôes consensuais entre os entes federativos implicados "nesse fazer" estão legitimadas para definir, em detalhes, as responsabilidades postas (VIANA; LIMA, 2011; SANTOS; ANDRADE, 2012). Por isso, é necessário que a articulação interfederativa seja uma aliada para a consolidação da regionalização e dos espaços de governança, ainda que o pacto federativo do Brasil e os arranjos organizativos do SUS com base municipal gerem dificuldades, justamente para sua organização (MIRANDA; MENDES; SILVA, 2017; SOUZA; SANTOS, 2018).

No estudo, as evidências constatam que a predominância na discussão e no monitoramento dos instrumentos normativos de planejamento é uma marca na região. O Plano Municipal de Saúde, o Relatório Anual de Gestão e a Programação Anual de Saúde demonstraram um cumprimento burocrático desses instrumentos de pactuação de metas e indicadores regionais, conforme a figura 1 . 
Figura 1. Mapa da II Região de Saúde-PE: municípios e instrumentos de planejamento. Recife-PE, 2018

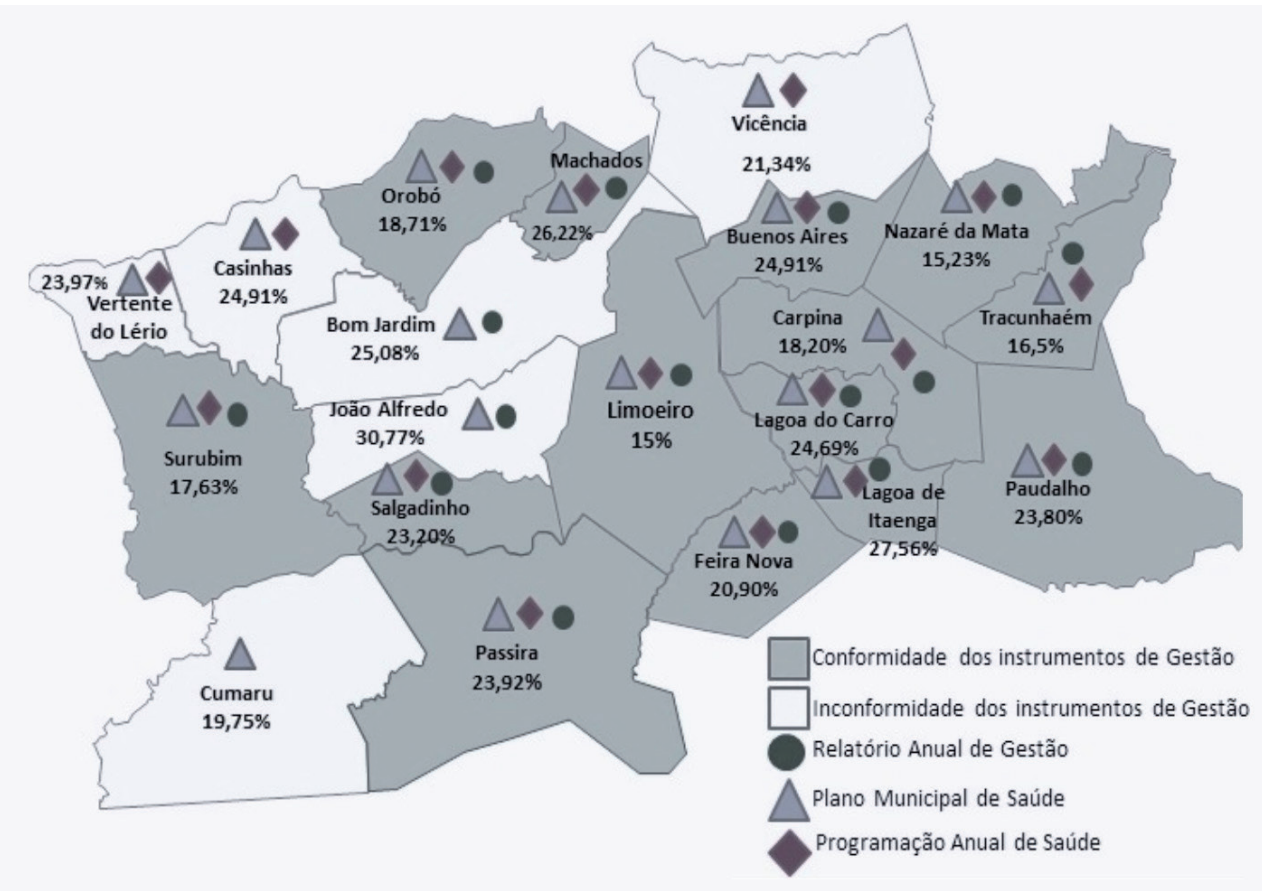

Fonte: elaboração própria.

Gil, Luiz e Gil (2016) apontam que essa forma de trabalho tem tido baixa eficácia quando comparada ao planejamento estratégico, pois este consegue mobilizar e envolver todos os indivíduos inseridos no processo de saúde. No mesmo direcionamento, Silveira Filho et al. (2016) relatam que as reuniōes de CIR foram marcadas por debates quanto aos atrasos na elaboraçáo e entrega dos instrumentos normativos de planejamento. Ainda segundo os autores, quanto aos atrasos, o fato compromete a execução de um bom planejamento e a avaliação de açôes e serviços no âmbito municipal.

Albuquerque e Martins (2017) ratificam que o monitoramento e a pactuação de indicadores na região podem ter se tornado uma atividade meramente burocrática com baixa aderência às ações prioritárias de saúde. A baixa institucionalização do monitoramento e da avaliação nas práticas de saúde reforça a necessidade de qualificação dos atores, intensifica a pouca integração entre sistemas de informação 
e a permanência de ciclos viciosos, que geram praticas fragmentadas, as quais dificultam a institucionalização dos processos (CARVALHO et al., 2012). No estudo, o planejamento na regiáo é visto pelos gestores como importante ferramenta, embora ainda frágil e incipiente, com uma nítida necessidade de aprimoramento em seu uso. Nesse aspecto, ficou evidente a ausência de um instrumento específico de planejamento para a aplicação na região. O resultado similar de Bretas Júnior e Shimizu (2015) confirma que os gestores de saúde, apesar de reconhecerem o valor de planejar, praticam açóes mais voltadas para a manutenção do sistema vigente do que para gerar modificaçóes, com vistas à consolidação do SUS.

Ainda que a CIR e sua respectiva câmara técnica reforcem a necessidade de apropriação de técnicos e gestores quanto ao planejamento, verificou-se que a carência desse setor nas secretarias municipais de Saúde acarreta em dificuldades na formulação e execução do planejamento no nível local. Em suas evidências, Medeiros et al. (2017) confirmam não haver verificado o conhecimento dos gestores sobre a realidade regional, prevalecendo, ainda, as decisóes com embasamento mais político do que técnico. No mesmo sentido, Martins e Waclawovsky (2015) corroboram a existência de uma insuficiência nos ciclos de planejamento dentro das estruturas de saúde.

É válido destacar que a constante repactuação, quanto à recomposição da Câmara Técnica, pode indicar um comprometimento da condução técnica de assessoramento destas reunióes, acarretando descontinuidade das construçôes técnico-políticas que comprometem o processo de governança no sistema regionalizado. Mendes (2011) coloca que, apesar da grande importância, a CIR e a Câmara Técnica, por si sós, não são suficientes para garantia de uma boa governança, considerando que não há um sistema gerencial permanente que conduza a tomada de decisão.

Diante das evidências, o triângulo de ferro de Matus (1996), composto pelo projeto de governo (a proposta de meios e objetivos de mudança para uma situação desejada), a capacidade de governo (a habilidade para alcance dessas mudanças) e a governabilidade (o caminho que o governo deve percorrer para o sistema de direção e planejamento), reforça a noção de problemas relevantes, prioritários e estratégicos que deve ser adotada pelos gestores na regiáo (MATUS, 1996).

Por meio da análise de documentos e das respostas dos sujeitos entrevistados, foram categorizadas as forças, as oportunidades, as fraquezas e as ameaças na região (quadro 2). O uso da ferramenta SWOT permite uma análise sistemática por meio 
da identificação dessas variáveis que, quando confrontadas se tornam um importante mecanismo para o diagnóstico e tomada de uma decisão.

Quadiro 2. Aplicação da ferramenta SWOT no diagnóstico situacionnal da regiáo. Recife-PE, 2018

\begin{tabular}{|c|c|}
\hline $\begin{array}{l}\text { FORÇAS (Strengths) } \\
\text { Interno }\end{array}$ & $\begin{array}{c}\text { FRAQUEZAS (Weaknesses) } \\
\text { Interno }\end{array}$ \\
\hline $\begin{array}{l}\text { - Reconhecimento da potencialidade da CIR } \\
\text { como espaço para governança em saúde; } \\
\text { - Alta assiduidade dos gestores e outros atores } \\
\text { na CIR; } \\
\text { - Percepçáo dos gestores quanto ao turnover } \\
\text { desse cargo na região; } \\
\text { - A CIR como importante instrumento para as } \\
\text { relaçóes interfederativas; } \\
\text { - Percepçáo dos gestores na CIR quanto a } \\
\text { execução desgastada da PPI; } \\
\text { - Percepção dos gestores na CIR quanto ao } \\
\text { subfinanciamento do SUS; } \\
\text { - Percepção dos gestores quanto à alta } \\
\text { participaçáo da iniciativa privada } \\
\text { complementar na região; }\end{array}$ & $\begin{array}{l}\text { - Ausência da discussão sobre educação } \\
\text { - Prermanente; } \\
\text { normativos de planejamento; } \\
\text { - Ausência do monitoramento e avaliação em } \\
\text { saúde; } \\
\text { - Carência de planejamento a nível municipal; } \\
\text { - Constantes repactuaçóes da Câmara Técnica; } \\
\text { - Cartorialização dos instrumentos de pactuação; } \\
\text { - Desconhecimento do território para executar o } \\
\text { planejamento; }\end{array}$ \\
\hline $\begin{array}{c}\text { OPORTUNIDADES (Opportunities) } \\
\text { Externo }\end{array}$ & $\begin{array}{c}\text { AMEAÇAS (Threats) } \\
\text { Externo }\end{array}$ \\
\hline $\begin{array}{l}\text { - Necessidade de mais aprimoramento técnico } \\
\text { dos gestores de saúde; } \\
\text { - Planejamento Regional Integrado; } \\
\text { - Apoio solidário entre os entes federados; }\end{array}$ & $\begin{array}{l}\text { - Preocupação dos gestores na concentração de } \\
\text { serviços; } \\
\text { - Negociação política em detrimento da técnica; } \\
\text { - Influência do ente estadual na tomada de } \\
\text { decisão nos espaços de pactuaçáo; } \\
\text { - Descumprimento do pacto federativo no custeio } \\
\text { das ASPS; } \\
\text { - Subfinanciamento do SUS; } \\
\text { - Participaçáo dos serviços privados } \\
\text { complementares. }\end{array}$ \\
\hline
\end{tabular}

Fonte: elaboração própria.

$\mathrm{Na}$ categoria ameaças, chama atenção à ênfase dada pelos gestores, quanto à concentração dos serviços de média e alta complexidade na capital e seu entorno, bem como no polo regional que situa a gerência regional. Com evidências semelhantes no estado de Pernambuco, Lemos (2014) já tinha observado forte centralização da 
oferta de serviços especializados na I Macrorregiáo de Saúde, onde se localiza a capital do estado, e para onde se destina parte expressiva dos usuários do estado.

Com a melhoria nas condiçóes de vida da Regiâo Nordeste e na oferta de serviços concentrados em poucas regiôes, houve grande variação de fluxos de pacientes com deslocamentos entre macrorregiôes e estados do país para a obtenção de determinados serviços, gerando vazios assistenciais. Uma das possíveis explicaçôes estaria relacionada aos investimentos e à expansão de atividades econômicas que mantiveram a tendência histórica de concentração nas capitais e em tradicionais polos regionais (ALBUQUERQUE et al., 2017; OLIVEIRA et al. 2004).

Esses resultados permitiram visualizar a forte atuação dos serviços complementares na região, sobretudo nos exames e diagnósticos, que mesmo regionalizados e regulados pelo estado, por meio da Gerência Regional de Saúde, ainda apresentam filas de espera e absenteísmo nas consultas. Para Santos e Giovanella (2014), a atuação dos serviços complementares, aqueles contratualizados com prestadores, ganham maior envergadura nos territórios com menor capacidade gestora para atuar na regulação assistencial ou em municípios cujos serviços conveniados se tornaram parceiros das correntes políticas que exercem o poder, ao ponto de privilegiarem os interesses particulares em detrimento do interesse público.

Mesmo que a forte atuação da gestão estadual de saúde tenha atuado na conformação de um complexo regulador compartilhado com os municípios, o acesso equânime e integral aos usuários ainda parece ser um desafio a ser superado. Nessa seara, a geografia pode ser um fator decisivo para uma correta operacionalização regional dos serviços de saúde. Quando não levada em consideração, pode gerar regiōes dissonantes com as realidades locais (ALBUQUERQUE et al., 2017; DUARTE et al., 2015). Pode-se identificar um amplo debate sobre a organização e pactuação dos serviços regionalizados com foco na ampliação da Rede de Atenção à Saúde (RAS), a partir da qual alguns equipamentos se tornaram referência na oferta de serviços e consultas, pois permitem, aos municípios da regiáo, o acesso de seus munícipes aos serviços não ofertados no seu território.

As regiốes de saúde ainda são fortemente marcadas pela expansão da RAS, com maior intensidade na atençáo especializada, que concentra atualmente boa parte dos recursos necessários para a assistência à saúde (ERDEMANN; ANDRADE; MELLO, 2013; SANTOS et al., 2015). Ainda que exista uma tentativa do fortalecimento das redes regionalizadas para possíveis reduçôes de custos, frente à 
racionalidade e à garantia das condiçôes de integralidade da atenção, os desafios são grandes, como as relações entre governos, os aspectos da descentralização dos serviços de saúde e a integração de um modelo assistencial, tendo a Atenção Básica como ordenadora do cuidado (GOMES, 2014).

Para além, o mapa da saúde tido como importante instrumento de delineamento da RAS, que deveria subsidiar o planejamento integrado e o estabelecimento de metas de saúde, não foi observado na região. A ausência desse instrumento ratifica os desafios postos à conformação dos serviços regionalizados. A região precisa ser um espaço potente de cooperaçáo, baseado no cumprimento de metas e resultados, sobretudo nas tomadas de decisão por meio do monitoramento e da avaliação dos serviços de saúde. Ademais, precisa se constituir como um espaço importante para a integralidade, já que é no território que a saúde tem início e fim (VIANA et al., 2018; MENDES, 2011).

A análise realizada reacende a necessidade de buscar novos caminhos e metodologias para o fortalecimento da gestáo, considerando o ambiente interno e o ambiente externo que envolve a regiāo. Apesar da importância conferida pelos gestores, neste estudo, sobre a temática do financiamento, observou-se uma descontinuidade na discussão sobre a execução dos recursos referentes à pactuação dos serviços de saúde na regiâo. Os gestores consideraram a aplicação da Programação Pactuada Integrada (PPI) desgastada, o que promove uma regulação discrepante das reais necessidades dos municípios.

Moreira e Tamaki (2017), com resultados semelhantes, observaram que a PPI não está desempenhando seu papel de instrumento garantidor do acesso da população a serviços de maior complexidade. Os municípios não acompanham sua execução, desconhecendo a realidade e impedindo a realização de cobranças.

A discussão esteve mais associada ao financiamento e à própria desatualização da PPI do que, especificamente, às centrais de marcação de consultas ou à regulação dos fluxos. Nesse sentido, as açôes de saúde acabam apresentando divergências e dificuldades na definiçáo das prioridades, o que torna evidente as dificuldades em prover o acesso aos serviços de saúde (SILVEIRA FILHO et al., 2016; SANTOS et al., 2015; GOYA et al., 2017). Verificou-se a preocupaçáo dos gestores quanto ao subfinanciamento do SUS e do comprometimento do pacto federativo no custeio de Açôes e Serviços Públicos de Saúde, que interferem no processo de governança na região. Nessa lógica, a concessão de financiamento do governo federal para alguns 
programas de saúde, sem o devido compromisso com os estados e municípios, acaba favorecendo a ampliação dos serviços de saúde e o recebimento de um custeio que nem sempre tem sido garantido, forçando os municípios a investirem mais. Esta é uma ampla questão, sobretudo em relação ao acesso, quando a abertura de novos serviços não o garantem (DAVID; SHIMIZU; SILVA, 2015; MENDES; MARQUES, 2014).

Estudos realizados demonstram que à medida que as contrapartidas do ente estadual e federal decaem, exige-se do ente municipal a aplicação superior ao percentual mínimo determinado pela legislação, ainda que esse fato não gere uma garantia para execução integral desses recursos (LOUVISON; MENDES, 2015; FUNCIA; SANTOS, 2019; MAZON et.al, 2018).

Outro fator que merece destaque é o novo regime fiscal brasileiro advindo da Emenda Constitucional $n^{\circ} 95$ de 2016, que limitou os gastos públicos pelo período de 20 anos, interferindo diretamente no planejamento e na governança do SUS (ROSSI; DWECK, 2016; REIS et al., 2016). O financiamento deveria representar um aspecto importante para o fortalecimento da descentralização da política de saúde, com vistas à maior autonomia municipal no uso dos recursos financeiros, mas sua recente forma de operacionalização resultou na ampliação de uma transferência de recursos fragmentada e condicionada em forma de incentivo, sobretudo para açôes de saúde de média e alta complexidade (DUARTE; MENDES; LOUVISON, 2018).

\section{Considerações finais}

Percebeu-se a potencialidade da CIR como um espaço fundamental para a governança na região. Suas reunióes ocorrem com boa assiduidade e participação dos gestores na arena de decisões. Em contraponto, ficou clara a necessidade de maior apropriação técnica aos gestores, uma vez que seus relatos reacendem a necessidade de se buscar novos caminhos para o fortalecimento da gestáo.

O papel e a atuação da CIR evidenciam que as relaçóes interfederativas se tornaram um mecanismo fundamental para o fortalecimento da governança em saúde. A expressão "parceria", comungada entre os gestores, demonstra uma realidade já perpetrada dentro da região de saúde, reforçando o aspecto da gestão solidária entre os entes para enfrentamento dos desafios e a consolidação da regionalização em saúde. Em contrapartida, a mudança de gestores, os atravessamentos políticos-partidários e os aspectos relativos às pactuaçóes, envolvendo o financiamento das açôes e serviços, interferem no processo decisório e dificultam a governança na região. 
Em relação ao planejamento em saúde, a região é estritamente marcada por instrumentos normativos de planejamento. A ausência da construçáo acerca das causas e consequências dos problemas, por meio de instrumentos de planejamento estratégico, apenas ratifica a necessidade da busca de cálculos que precedem e presidem a ação.

Outro aspecto importante diz respeito à morosidade relativa à implantação dos dispositivos previstos no Decreto 7.508/11. A afirmação de que não existe dinheiro novo, da inexecução da PPI e da falta de atualização da tabela SUS apenas corrobora os desafios no tocante aos pactos interfederativos que interferem no planejamento e na governança em saúde. Mesmo que se verifiquem diversos aspectos acerca do planejamento e da governança regional, é imprescindível que novos estudos sejam realizados sobre o tema, para que possam subsidiar gestores e estudiosos no enfrentamento de desafios postos para sua consolidação na política pública de saúde brasileira.

A negociação pode ser vista como uma poderosa ferramenta para auxiliar a gestão na regiấo, pois permite a mediação dos interesses dos atores envolvidos e o desenvolvimento de um projeto cujo objetivo é a melhoria do acesso aos serviços e da qualidade prestada à populaçáo. Além disso, a criação de estratégias no processo de educação permanente, como grupos de trabalhos vinculados à CIES, pode ser um importante instrumento para o fortalecimento da educação em saúde voltada para a prática do planejamento e da governança na regiáo por meio de uma metodologia baseada na problematização das práticas cotidianas com equipes multidisciplinares, permitindo reflexóes críticas e a articulação de soluçóes estratégicas coletivas. ${ }^{1}$

\section{Referências}

ALBUQUeRQUe, C.; MARTINS, M. Indicadores de desempenho no Sistema Único de Saúde: uma avaliação dos avanços e lacunas. Saúde em Debate. Rio de Janeiro, v. 41, n. esp, p. 118-137, 2017. Disponível em: http://www.scielo.br/pdf/sdeb/v41nspe/0103-1104-sdeb-41nspe-0118.pdf. Acesso em: 28 dez. 2018.

ALBUQUERQUE, M. V. et al. Desigualdades regionais na saúde: mudanças observadas no Brasil de 2000 a 2016. Ciência e Saúde Coletiva, Rio de Janeiro, v. 22, n. 4, p. 1055-1064, 2017. Disponível em: http://www.scielo.br/pdf/csc/v22n4/1413-8123-csc-22-04-1055.pdf. Acesso em: 15 dez. 2018. 
ALMEIDA, P. F. et al. Integração assistencial em região de saúde: paradoxo entre necessidades regionais e interesses locais. Saúde e Sociedade, São Paulo, v. 25, n. 2, p. 320-335, 2016. Disponível em: http://www.scielo.br/pdf/sausoc/v25n2/1984-0470-sausoc-25-02-00320.pdf. Acesso em: 16 abr. 2018.

ARCARI, J. M. et al. Perfil do gestor e práticas de gestão municipal no sistema único de Saúde (SUS) de acordo com porte populacional nos municípios do estado do Rio Grande do Sul. Ciência e Saúde Coletiva. Disponível em: http:/www.cienciaesaudecoletiva.com.br/artigos/ perfil-do-gestor-e-praticas-de-gestao-municipal-no-sistema-unico-de-saude-sus-de-acordocom-porte-populacional-nos-municipios-do-estado-do-rio-grande-do-sul/16876?id=16876. Acesso em: 23 dez. 2018.

BARDIN, L. Análise de conteúdo. 6 ed. Lisboa: Almedina, 2011. 280p.

BRETAS JÚNIOR, N.; SHIMIZU, H. E. Planejamento regional compartilhado em Minas Gerais: avanços e desafios. Saúde em Debate, Rio de Janeiro, v. 39, n. 107, p. 962-971, 2015. Disponível em: http://www.scielo.br/pdf/sdeb/v39n107/0103-1104-sdeb-39-10700962.pdf. Acesso em: 19 dez. 2018.

CARVALHO, A. L. B. et al. A gestão do SUS e as práticas de monitoramento e avaliação: possibilidades e desafios para a construção de uma agenda estratégica. Ciência e Saúde Coletiva. Rio de Kaneiro, v. 17, n. 4, p. 901-11, 2012. Disponível em: https://www.scielo.br/scielo. php?script=sci_arttext\&pid=S1413-81232012000400012. Acesso em: 23 dez. 2018.

DALLABRIDA, V. R. Governança territorial e desenvolvimento: descentralização políticoadministrativa, estruturas subnacionais de gestáo do desenvolvimento e capacidades estatais. Rio de Janeiro: Editora Garamond, 2011. p. 15-38.

DAVID, G. C.; SHIMIZU, H. E.; SILVA, E. N. Atenção Primária à Saúde nos municípios brasileiros: eficiência e disparidades. Saúde em Debate, Rio de Janeiro, v. 39, n. esp, p. 232-245, 2015. Disponível em: http://www.scielo.br/pdf/sdeb/v39nspe/0103-1104-sdeb-39-spe-00232. pdf. Acesso em: 20 nov. 2018.

DOURADO, D. A.; ELIAS, P. E. M. Regionalização e dinâmica política do federalismo sanitário brasileiro. Revista de Saúde Pública, São Paulo, v. 45, n. 1, p. 204-211, 2011.Disponível em: http://www.scielo.br/pdf/rsp/v45n1/1944.pdf. Acesso em: 20 dez. 2018.

DUARTE, L. S. et al. Regionalização da saúde no Brasil: uma perspectiva de análise. Saúde e Sociedade, São Paulo, v. 24, n. 2, p. 472-485, 2015. Disponível em: http://www.scielo.br/pdf/ sausoc/v24n2/0104-1290-sausoc-24-02-00472.pdf. Acesso em: 16 abr. 2018.

DUARTE, L. S.; MENDES, A. N.; LOUVISON, M. C. P. O processo de regionalização do SUS e a autonomia municipal no uso dos recursos financeiros: uma análise do estado de Sáo Paulo (2009-2014). Saúde em Debate, Rio de Janeiro, v. 42, n. 116, p. 25-37, 2018. Disponível em: http:// www.scielo.br/pdf/sdeb/v42n116/0103-1104-sdeb-42-116-0025.pdf. Acesso em:18 dez. 2018. 
ERDEMANN, A. L.; ANDRADE, S. R.; MELLO, A. L. S. A atenção secundária em saúde: melhores práticas na rede de serviços. Revista Latino-Americana de Enfermagem,v. 21, n. esp., jan-fev 2013. Disponível em: http://www.scielo.br/pdf/rlae/v21nspe/pt_17.pdf. Acesso em: 14 dez. 2018.

FLEURY, S. Uma rica avaliaçâo da construção da gestão democrática da saúde no nível local. Rio de Janeiro: Cebes: Editora Fiocruz, 2014.

FLEURY, S.; OUVERNEY, A. M. Política de saúde: uma política social. In: GIOVANELLA, L. et al. Políticas e sistema de saúde no Brasil. 2 ed. Rio de Janeiro: Editora Fiocruz, 2012.

FRANÇA, E. B. et al. Principais causas da mortalidade na infância no Brasil, em 1990 e 2015: estimativas do estudo de carga global de doença. Revista Brasileira de Epidemiologia, São Paulo, v. 20, supl. 1, p. 46-60, mai. 2017. Disponível em: http://www.scielo.br/pdf/rbepid/v20s1/19805497-rbepid-20-s1-00046.pdf. Acesso em: 10 dez. 2019.

FUNCIA, F. R.; SANTOS, L. Do subfinanciamento ao desfinanciamento da saúde: descendo as escadas. Domingueiras da Saúde, n. 4, 2019. Disponível em: http://idisa.org.br/domingueira/ domingueira-n-04-janeiro-2019. Acesso em: 28 jan. 2019.

GIL, C. R. R.; LUIZ, G. C.; GIL, M. C. R. (Org.). A importância do planejamento na gestão do SUS. São Luís: Edufma, 2016.

GOMES, R. M. Redes de Atenção à Saúde do SUS: 25 anos de uma contradição fundamental entre a Organização Necessária e a Organização Atual. Saúde em Debate. Rio de Janeiro, v. 38, n. 103, p. 938-952, 2014. Disponível em: http://www.scielo.br/pdf/sdeb/v38n103/0103-1104sdeb-38-103-0938.pdf. Acesso em: 16 out. 2018.

GOYA, N. et al. Percepçóes de gestores estaduais da saúde sobre o Contrato Organizativo da Ação Pública da Saúde no Ceará, Brasil. Ciência e Saúde Coletiva, v. 22, n. 4, p. 1235-1244, 2017. Disponível em: http://www.scielo.br/pdf/csc/v22n4/1413-8123-csc-22-04-1235.pdf. Acesso em: 16 abr. 2018.

LEMOS, C. L. S. Educação Permanente em Saúde no Brasil: educação ou gerenciamento permanente? Ciência e Saúde Coletiva, Rio de Janeiro, v. 21, n. 3, p. 913-922, 2016. Disponível em: http://www.scielo.br/pdf/csc/v21n3/1413-8123-csc-21-03-0913.pdf. Acesso em: 14 dez 2018.

LEMOS, R. S. Regionalização da alta complexidade em saúde no estado de Pernambuco: oferta e alocação de recursos. Dissertação (Mestrado em Gestão e Economia da Saúde) - Universidade Federal de Pernambuco, Recife, 2014.

LIMA, L. D. et al. Arranjos de governança da assistência especializada nas regiōes de saúde do Brasil. Revista Brasileira de Saúde Materno Infantil. Recife, v. 17, n. 1, p. 121-133, 2017. Disponível em: http://www.scielo.br/pdf/rbsmi/v17s1/pt_1519-3829-rbsmi-17-s1-S107.pdf. Acesso em: 16 abr. 2018. 
LIMA, L. D.; VIANA, A. L. D., MACHADO, C. V. A regionalização da saúde no Brasil: condicionantes e desafios. In: SCATENA, J. H. G.; KEHRIG, R. T.; SPINELLI, M. A. (Orgs.). Regióes de Saúde: diversidade e processo de regionalização em Mato Grosso. São Paulo: Hucitec, 2014. p. 565.

LORENZETTI, J. et al. Gestâo em saúde no Brasil: diálogo com gestores públicos e privados. Texto e Contexto Enfermagem, Florianópolis, v. 23, n. 2, p. 417-425, 2014. Disponível em: http:// www.scielo.br/pdf/tce/v23n2/pt_0104-0707-tce-23-02-00417.pdf. Acesso em: 22 dez. 2019.

LOUVISON, M.; MENDES, A. O debate da regionalizaçáo em tempos de turbulência no SUS. Saúde e Sociedade, São Paulo, v. 24, n. 2, p. 393-402, 2015. Disponível em: http://www. scielo.br/pdf/sausoc/v24n2/0104-1290-sausoc-24-02-00393.pdf. Acesso em: 16 abr. 2018.

MARTINS, C. C.; WACLAWOVSKY, A. J. Problemas e desafios enfrentados pelos gestores públicos no processo de gestão em saúde. Revista de Gestão em Sistemas de Saúde, v. 4, n. 1, 2015. Disponível em: http://www.revistargss.org.br/ojs/index.php/rgss/article/view/157/156. Acesso em: 14 dez. 2018.

MATUS, C. Estratégias políticas: Chimpanzé, Maquiavel e Gandhi. São Paulo: Edições Fundap, 1996.

MAZON, L. M. et al. Execução financeira dos blocos de financiamento da saúde nos municípios de Santa Catarina, Brasil. Saúde em Debate, Rio de Janeiro, v. 42, n. 116, p. 38-51, 2018. Disponível em: http://www.scielo.br/pdf/sdeb/v42n116/0103-1104-sdeb-42-116-0038. pdf. Acesso em: 20 jan. 2019.

MEDEIROS, C. R. G. et al. Planejamento regional integrado: a governança em região de pequenos municípios. Saúde e Sociedade, São Paulo, v. 26, n. 1, p. 129-140, 2017. Disponível em: http://www.scielo.br/pdf/sausoc/v26n1/1984-0470-saudesoc-26-01-00129.pdf. Acesso em: 16 abr. 2018 .

MEDEIROS, C. R. G. Redes de atençâo em saúde: o dilema dos pequenos municípios. 2013. 203f. Tese. (Doutorado em Enfermagem) - Universidade Federal do Rio Grande do Sul, Porto Alegre, 2013.

MENDES, A. et al. O processo de construção da gestão regional da saúde no estado de São Paulo: subsídios para a análise. Saúde Sociedade, São Paulo, v. 24, n. 2, p. 423-437, 2015. Disponível em: http://www.scielo.br/pdf/sausoc/v24n2/0104-1290-sausoc-24-02-00423.pdf. Acesso em: 16 abr. 2018.

MENDES, A.; MARQUES, R. M. O financiamento da Atenção Básica e da Estratégia Saúde da Família no Sistema Único de Saúde. Saúde em Debate, Rio de Janeiro, v. 38, n. 103, p. 900-916, 2014. Disponível em: http://www.scielo.br/pdf/sdeb/v38n103/0103-1104-sdeb-38-103-0900. pdf. Acesso em: 10 nov. 2018. 
MENDES, E. V. As redes de atenção à saúde. Brasília, Organização Pan-Americana da Saúde, 2011. MENDES, E. V. As redes de atenção à saúde. Ciência e Saúde Coletiva, Rio de Janeiro, v. 15, n. 5, p. 2297-305, 2010. Disponível em: http://scielo.br/scielo.php?script=sci_arttext\&nrm=iso\&l ng=pt\&tlng=pt\&pid=S1413-81232010000500005. Acesso em: 15 dez. 2018.

MILAGRES, R.; SILVA, S. A. G.; REZENDE, O. Governança colaborativa. Conass Debate: governança regional das Redes de Atenção à Saúde. Brasília: Ministério da Saúde, 2016.

MIRANDA, G. M. D.; MENDES, A. C. G.; SILVA, A. L. A. O desafio da organização do Sistema Único de Saúde universal e resolutivo no pacto federativo brasileiro. Saúde e Sociedade, São Paulo, v. 26, n. 2, p. 329-335, 2017. Disponível em: http://www.scielo.br/pdf/sausoc/ v26n2/1984-0470-sausoc-26-02-00329.pdf. Acesso em: 15 dez 2018.

MOREIRA, L. C. O.; TAMAKI, E. M. A Programaçâo Pactuada e Integrada como instrumento de garantia da integralidade da atenção à saúde no SUS. Interações. Campo Grande, v. 18, n. 4, p. 99-108, 2017. Disponível em: http://www.scielo.br/pdf/inter/v18n4/1518-7012inter-18-04-0099.pdf. Acesso em: 19 dez. 2018.

MOREIRA, M. R.; RIBEIRO, J. M.; OUVERNEY, A. M. Obstáculos políticos à regionalização do SUS: percepçóes dos secretários municipais de Saúde com assento nas Comissóes Intergestores Bipartites. Ciência e Saúde Coletiva, Rio de Janeiro, v. 22, n. 4, p. 1097-1108, 2017. Disponível em: http://www.scielo.br/scielo.php?script=sci_arttext\&pid=\$141381232017002401097\&lng= en\&nrm=iso. Acesso em: 15 dez. 2018.

PAIM, J. S.; TEIXEIRA, C. F. Política, planejamento e gestão em saúde: balanço do estado da arte. Revista de Saúde Pública, São Paulo, v. 40, n. esp., p. 73-78, 2006. Disponível em: http:// www.scielo.br/pdf/rsp/v40nspe/30625.pdf. Acesso em: 10 jan. 2019.

REIS, A. A. C. et al. Tudo a temer: financiamento, relação público e privado e o futuro do SUS. Saúde em Debate, Rio de Janeiro, v. 40, n. esp., p. 122-135, 2016. Disponível em: http://www. scielo.br/pdf/sdeb/v40nspe/0103-1104-sdeb-40-spe-0122.pdf. Acesso em: 12 dez. 2018.

RICARDI, L. M.; SHIMIZU, H. E.; SANTOS, L. M.P. As Conferências Nacionais de Saúde e o Processo de Planejamento do Ministério da Saúde. Saúde Debate, Rio de Janeiro, v. 41, n. 3, p. 155-170, 2017. Disponível em: http://www.scielo.br/pdf/sdeb/v41nspe3/0103-1104-sdeb-41spe3-0155.pdf. Acesso em: 14 nov. 2018.

ROSSI, P.; DWECK, E. Impactos do novo regime fiscal na saúde e educação. Cadernos de Saúde Pública, Rio de Janeiro, v. 32, n. 12, 2016. Disponível em: http://www.scielo.br/pdf/csp/ v32n12/1678-4464-csp-32-12-e00194316.pdf. Acesso em: 15 dez. 2018.

SANTOS, A. M.; GIOVANELLA, L. Governança regional: estratégias e disputas para gestão em saúde. Revista de Saúde Pública, São Paulo, v. 48, n. 4, p. 622-631, 2014. Disponível em: http:// www.scielo.br/pdf/rsp/v48n4/pt_0034-8910-rsp-48-4-0622.pdf. Acesso em: 15 dez. 2018. 
SANTOS, E. R. R.; LEITE, A. F. B.; SILVA, A. P. S. C. Tomada de decisáo no cotidiano do gestor de saúde: tecnologias, instrumentos e estratégias de atuação. Recife: Ed. UFPE, 2018.

SANTOS, F. A. S. et al. A regionalização e financiamento da saúde: um estudo de caso. Cadernos de Saúde Coletiva, Rio de Janeiro, v. 23, n. 4, p. 402-408, 2015. Disponível em: http:// www.scielo.br/pdf/cadsc/v23n4/1414-462X-cadsc-23-4-402.pdf. Acesso em: 16 abr. 2018.

SANTOS, L. Região de Saúde e suas redes de atenção: modelo organizativo-sistêmico do SUS. Ciência e Saúde Coletiva, Rio de Janeiro, v. 22, n. 4, 2017. Disponível em: https://www.scielosp. org/article/csc/2017.v22n4/1281-1289/. Acesso em: 22 abr. 2019.

SANTOS, L.; ANDRADE, L. O. M. Acesso às ações e aos serviços de saúde: uma visão polissêmica. Ciência e Saúde Coletiva, Rio de Janeiro, v. 17, n. 11, p. 2876-2878, 2012. Disponível em: http://www.scielo.br/pdf/csc/v17n11/v17n11a03.pdf. Acesso em: 10 nov. 2018.

SANTOS, L.; CAMPOS, G. W. S. SUS Brasil: a região de saúde como caminho. Saúde Sociedade, São Paulo, v. 24, n. 2, p. 438-446, 2015. Disponível em: http://www.scielo.br/pdf/ sausoc/v24n2/0104-1290-sausoc-24-02-00438.pdf. Acesso em: 16 abr. 2018.

SILVA, B. F. S. et al. A importância do planejamento como prática de gestão na microrregião de saúde de São Mateus (ES). Saúde Debate, Rio de Janeiro, v. 39, n. 104, p. 183-196, 2015. Disponível em: http://www.scielo.br/pdf/sdeb/v39n104/0103-1104-sdeb-39-104-00183.pdf. Acesso em: 12 dez. 2018.

SILVA, K. C. L.; SANTOS, E. R. R.; MENDES, M. S. O planejamento estratégico no processo de implementação da política de atenção primária em um município da região metropolitana do Recife, Pernambuco, Brasil. Journal of Management and Primary Health Care, v. 3, n. 1, p. 15-25, 2012. Disponível em: file://C:/Users/prpe/Downloads/113-Texto\%20do\%20 artigo-135-1-10-20150820\%20(1).pdf. Acesso em: 16 abr. 2018.

SILVEIRA FILHO, R. M. et al. Açôes da Comissão Intergestores Regional para gestão compartilhada de serviços especializados no Sistema Único de Saúde. Physis, Rio de Janeiro, v. 26, n. 3, p. 853-878, 2016. Disponível em: http://www.scielo.br/pdf/physis/v26n3/0103-7331physis-26-03-00853.pdf. Acesso em: 10 mar. 2019.

SOUZA, J. C. D.; SANTOS, A. O. Os desafios da regionalização do SUS no contexto federativo brasileiro. Cadernos Ibero-Americanos de Direito Sanitário, Brasília, v. 7, n. 2, p. 29-47, 2018. Disponível em: https://www.cadernos.prodisa.fiocruz.br/index.php/cadernos/article/view/478. Acesso em: 20 out. 2018.

VIANA, A. L. A.; LIMA, L. D. (Orgs.). Regionalização e relaçóes federativas na politica de saúde do Brasil. Rio de Janeiro: ContraCapa, 2011.

VIANA, R. P.; LIMA, L. D. Colegiados de Gestão Regional no estado do Rio de Janeiro: atores, estratégias e negociação intergovernamental. Physis. Rio de Janeiro, n. 23, v. 4, p. 1025-1049, 2013. Disponível em: http://www.scielo.br/pdf/physis/v23n4/02.pdf. Acesso em: 10 out. 2018. 
VIANA, A. L. et al. Regionalização e Redes de Saúde. Ciência e Saúde Coletiva, Rio de Janeiro, v. 23, n. 6, p. 1791-1798, 2018. Disponível em: http://www.scielo.br/pdf/csc/v23n6/1413-8123csc-23-06-1791.pdf. Acesso em: 10 out. 2018.

YIN, R. K. Estudo de caso: planejamento e métodos. 3 ed. Porto Alegre: Bookman, 2005.

\section{Nota}

${ }^{1}$ R. C. F. da Silva: conceitualização, curadoria de dados, análise formal, metodologia, redação e revisão do artigo. E. R. R. dos Santos: administração e supervisão do projeto de pesquisa, redaçáo e revisão do artigo. P. T. de L. Martelli e J. E. L. Sobrinho: administração e validação do projeto de pesquisa. C. C. L. Souto: administração do projeto de pesquisa, redação e revisão do artigo. 


\section{Abstract}

\section{Governance and planning from a regional health perspective}

The principle of SUS decentralization has come a long way since its foundation. The regulations over time pointed to a process of regionalization to the detriment of municipalization. The publication of Decree No. 7.508 / 11 legitimized the health regions and their respective agreement space for the preparation of planning and decision making. Considering such aspects, the study analyzed governance and health planning in the II Health Region of the State of Pernambuco, through a qualitative study, using document analysis from the minutes and guidelines of the Regional Inter-Management Commission and the analysis of the content of interviews semi-structured with municipal managers in the region. The results attested CIR's role in regional governance, despite the evident weaknesses in the regional planning process and in the structures of health care networks.

Keywords: health systems; regional health planning; governance. 